Article (refereed) - postprint

Kay, A.L.; Bell, V.A.; Guillod, B.P.; Jones, R.G.; Rudd, A.C. 2018. Nationalscale analysis of low flow frequency: historical trends and potential future changes. Climatic Change, 147 (3-4). 585-599.

https://doi.org/10.1007/s10584-018-2145-y

(C) Springer Science+Business Media B.V., part of Springer Nature 2018

This version available http://nora.nerc.ac.uk/518511/

NERC has developed NORA to enable users to access research outputs wholly or partially funded by NERC. Copyright and other rights for material on this site are retained by the rights owners. Users should read the terms and conditions of use of this material at

http://nora.nerc.ac.uk/policies.html\#access

This document is the authors' final manuscript version of the journal article, incorporating any revisions agreed during the peer review process. There may be differences between this and the publisher's version. You are advised to consult the publisher's version if you wish to cite from this article.

The final publication is available at Springer via https://doi.org/10.1007/s10584-018-2145-y

Contact CEH NORA team at noraceh@ceh.ac.uk

The NERC and CEH trademarks and logos ('the Trademarks') are registered trademarks of NERC in the UK and other countries, and may not be used without the prior written consent of the Trademark owner. 


\title{
National-scale analysis of low flow frequency: historical trends and potential future changes
}

\author{
Kay A.L. ${ }^{1}$, Bell V.A. ${ }^{1}$, Guillod B.P. ${ }^{2 *}$, Jones R.G. ${ }^{2,3}$, Rudd A.C. ${ }^{1}$ \\ ${ }^{1}$ Centre for Ecology \& Hydrology, Wallingford, UK \\ ${ }^{2}$ Environmental Change Institute, University of Oxford, Oxford, UK \\ ${ }^{3}$ Met Office Hadley Centre, Exeter, UK \\ *Current affiliations: Institute for Atmospheric and Climate Science, ETH Zurich, Zurich, Switzerland and \\ Institute for Environmental Decisions, ETH Zurich, Zurich, Switzerland
}

\section{Abstract}

The potential impact of climate change on hydrological extremes is of increasing concern across the globe. Here a national-scale grid-based hydrological model is used to investigate historical trends and potential future changes in low flow frequency across Great Britain. The historical analyses use both observational data (1891-2015) and ensemble data from a regional climate model (1900-2006). The results show relatively few significant trends in historical low flows (2- or 20-year return period), whether based on 7-day or 30-day annual minima. Significant negative trends seen in some limited parts of the country when using observational data are generally not seen when using climate model data. The future analyses use climate model ensemble data for both near-future and far-future timeperiods (2020-2049 and 2070-2099 respectively), which are compared to a baseline sub-period from the historical ensemble (1975-2004). The results show future reductions in low flows, which are generally larger in the south of the country, at the higher (20-year) return period, and for the later time-period. Reductions are more limited if the estimates of future potential evaporation include the effect of increased carbon dioxide concentrations on stomatal resistance. Such reductions in river flow could have significant impacts on the aquatic environment and on agriculture, and present a challenge for water managers, especially as reductions in water supply are likely to occur alongside increases in demand.

\section{Keywords}

Drought, low flows, river flow, hydrology, Great Britain

\section{Introduction}

There is a growing consensus that climate change will have a significant impact on the hydrological cycle across the globe, with particular concern about the effect on hydrological extremes; floods and droughts (Jiménez Cisneros et al. 2014). Hydrological droughts (i.e. deficits in river flow, or possibly in lake/reservoir/groundwater levels) are particularly important due to their detrimental impact on aquatic ecosystems and their effect on water supplies for human consumption (van Lanen et al. 2016). In Britain this was recently highlighted by the drought of 2010-2012, which had significant environmental impacts across the country and necessitated the introduction of a number of measures including hosepipe bans to conserve water supplies (Kendon et al. 2013). Fortunately this serious drought was terminated in spring/summer 2012, but only by accumulated rainfall totals with return periods in excess of 100 years (Bell et al. 2013).

Evidence of change in drought globally over the last half a century is mixed and apparently contradictory (Trenberth et al. 2014), with some studies suggesting little change (Sheffield et al. 2012) but others suggesting increases (Dai 2013). Prudhomme et al. (2014) analyse changes in runoff, from driving seven global impact models with data from five global climate models under four representative concentration pathways, and suggest a likely increase in the fraction of global land area under drought conditions by 2070-2099 compared to 1976-2005. However, Sperna Weiland et al. (2012) show that projections of changes in discharge vary substantially, both spatially 
and seasonally, with decreases in annual minimum discharge for large parts of Europe. Similarly, Roudier et al. (2016) look at potential future changes in extreme low flows (10- and 100-year return period) across Europe under a $2^{\circ} \mathrm{C}$ global warming scenario, and show increases in drought duration and decreases in flow to the south and west, but decreases in duration and increases in flow to the north and east. Arnell and Lloyd-Hughes (2014) suggest that, by 2050, between 0.92 and 3.4 billion people could experience increased water resources stress but between 0.35 and 2.9 billion people could experience decreased water resources stress (under a high emissions scenario and a 'middleof-the-road' average shared socio-economic pathway).

In Britain, analysis of gauged flows for a set of near-natural catchments suggests significant increasing trends in 7-day and 30-day minima in a small number of catchments, mostly to the north west of the country, for 1973-2002, but these were influenced by several dry years towards the start of the time-period and no significant trends were seen in an analysis covering 1963-2002 in these catchments or elsewhere (Hannaford and Marsh 2006). Future projections for river flows, based on the UK Climate Projections 2009 (UKCP09; Murphy et al. 2009), suggest a general reduction in summer flows across the country, with a more mixed picture for flows in the other seasons (Prudhomme et al. 2012, Christierson et al. 2012). Charlton and Arnell (2014) use the UKCP09 probabilistic projections for six catchments in England, and show reductions in Q95 (the flow exceeded $95 \%$ of the time) ranging between about $-75 \%$ and $-10 \%$ by the 2080 s.

In this study, a national-scale grid-based hydrological model is used with climate data from i) observations and ii) novel large ensembles of climate model runs, to investigate historical and potential future changes in low flows across Great Britain. The observation-based run of the hydrological model is used to assess whether there have been any significant trends in low flows anywhere in Britain, over 1891-2015. The observation-based results are compared to those from use of an historical climate model ensemble covering 1900-2006. Further climate model ensembles, covering near-future and far-future periods (2020-2049 and 2070-2099 respectively), are then used to assess potential future changes in low flows, compared to a baseline sub-period of the historical ensemble (1975-2004). The influence of using future potential evaporation (PE) estimates that include the effect of increased carbon dioxide concentrations on stomatal resistance is also assessed; this factor is often ignored when estimating PE for potential future climates.

\section{Methodology}

\subsection{Hydrological model}

The Grid-to-Grid (G2G) is a national-scale hydrological model for Great Britain that runs on a $1 \mathrm{~km}$ grid (aligned with the GB national grid), at a 15-minute time-step, and is parameterised using digital datasets (e.g. soil types) (Bell et al. 2009). It has previously been used to investigate potential changes in future flooding (Bell et al. 2012, 2016) and is used by the Flood Forecasting Centre for England and Wales and the Scottish Flood Forecasting Service (Price et al. 2012, Maxey et al. 2012). G2G performs well for a wide range of catchments across Britain (Bell et al. 2009), particularly those with more natural flow regimes as it currently does not include the effect of artificial influences like abstractions and discharges (e.g. effluent returns) on river flows. It has recently been shown to perform well specifically for low flows and for drought identification (Rudd et al. 2017).

G2G requires input time-series of precipitation and PE (Section 2.2). The optional snow module (Bell et al. 2016) is not used here due to limited availability of the required daily minimum and maximum temperature data. Although this needs to be borne in mind, its effect on drought is likely to be limited. Flow regimes are rainfall-dominated in the vast majority of the country (Kay 2016), although snow melt can support summer flows in some catchments draining the Scottish highlands for example, where significant snow can accumulate over winter and melt slowly (Soulsby et al. 1997). 


\subsection{Driving data}

Two sets of climate data are used to drive the hydrological model, one using observational data and one using climate model data.

The observation-based run of the hydrological model (OBS hereafter) covers 1889-2015, and uses $1 \mathrm{~km}$ grids of daily rainfall from CEH-GEAR (Keller et al. 2015, Tanguy et al. 2016) and $5 \mathrm{~km}$ grids of monthly PE derived from monthly temperature data using the method of Oudin et al. (2005) (see Rudd et al. (2017) for more detail, including bias-correction of temperature-based PE towards more physically-based PE). The PE are copied to each of the corresponding $1 \mathrm{~km}$ boxes of the hydrological model grid, and both PE and rainfall are divided equally down to the 15-minute model time-step.

The climate model data are produced by the Weather@Home (WaH) system, which uses volunteer computing time to do large numbers of runs of the HadRM3P regional climate model (RCM) nested in the HadAM3P atmospheric global climate model (GCM), with prescribed sea-surface temperatures (SSTs) and sea-ice conditions (Massey et al. 2015). An updated version with a more sophisticated land surface scheme, WaH2 (Guillod et al. 2017), is used here. Each individual WaH2 simulation only covers 13 months (from $1^{\text {st }}$ December), but they are stitched together using a novel technique based on soil moisture in the overlapping Decembers, resulting in 100-member ensembles covering three time-periods - Historical (HIST; 1900-2006), Near-Future (NF; 2020-2049) and Far-Future (FF; 20702099) (Guillod et al. 2018). The Baseline (BS) time-period from the Historical ensemble, against which future changes should be compared, is 1975-2004, and the Near-Future and Far-Future ensembles use the RCP 8.5 emissions scenario (Riahi et al. 2011). Guillod et al. (2018) produce five alternative sets of Near-Future and Far-Future ensembles, with varying SST warming patterns derived from CMIP5 climate models; only those based on the median SST pattern are used here.

Ensemble data from each time-period are used to drive G2G. The available variables include the required precipitation and $\mathrm{PE}$, which are copied from the $0.22^{\circ}(\sim 25 \mathrm{~km})$ rotated lat-lon RCM grid to the corresponding $1 \mathrm{~km}$ boxes of the G2G grid, with additional weighting based on standard average annual rainfall patterns to provide a spatially non-uniform distribution of precipitation within each RCM box (Bell et al. 2007). The RCM uses 360-day years (12x30-day months), and a simple biascorrection scheme, based on monthly multiplicative factors, has been applied to precipitation (Guillod et al. 2018).

$\mathrm{PE}$ is derived from other climate variables using the Penman-Monteith scheme (Monteith 1965). For the historical time-period, the calculation uses monthly stomatal resistance $\left(r_{s}\right)$ values from the Met Office Rainfall and Evaporation Calculation Scheme (MORECS; Hough and Jones 1997). For the future time-periods two versions of $\mathrm{PE}$ are produced, one using the same $r_{s}$ values as the Historical timeperiod (NF_fixrs and FF_fixrs), and one using values adjusted to allow for closure of stomata under increased carbon dioxide concentrations (NF_adjrs, FF_adjrs) (Rudd and Kay 2016). See Guillod et al. (2018) for more detail, including the $r_{s}$ values applied. Using adjusted $r_{s}$ values substantially reduces the increase in PE between baseline and future time-periods, compared to using fixed $r_{s}$ (Guillod et al. 2018 Figs 14, S17-S19). Note that, unlike precipitation, PE is not bias-corrected (Guillod et al. 2018 Section 4.1.2); this should be borne in mind when interpreting the results. Note also that use of Penman-Monteith PE is preferred over temperature-based PE, due to inclusion of other climate variables affecting PE (e.g. humidity and wind), but the limited availability of observed time-series of these variables for historical periods means that they cannot be used to estimate PE for the observation-based run. This complicates comparison of results from the historical ensemble runs and the observation-based run (see later).

\subsection{Low flow frequency}

Two common low flow measures are used to investigate changes in low flow frequency; the 7- and 30-day annual minimum (AMIN7 and AMIN30) flows (Svensson et al. 2005). Grids of AMINn are saved for each year of each G2G model run by calculating the running mean of flows simulated over $\mathrm{n}$ days then saving the minimum in each calendar year. Low flow frequency curves are fitted to sets 
of AMINn for each grid point, using the generalised extreme value (GEV) distribution and the method of L-moments (Zaidman et al. 2002), resulting in grids of low flows with specific return periods (2- and 20-years). Note that this method assumes statistical independence and stationarity. Two successive annual minima may not be independent in some years in some areas (e.g. where there is significant groundwater storage), but tests for independence are unreliable where the sample size is small, and methods to account for dependence are highly complex (Zaidman et al. 2002), thus are not considered here.

For the extended time-periods covered by the OBS run (1889-2015) and the HIST ensemble runs (1900-2006), a moving window approach is applied to enable analysis of low flow trends. The window, of length 30-years, is moved through each AMIN time-series (neglecting the first two years to allow for model spin up, Rudd et al. 2017). A low flow frequency curve is fitted at each position of the window, resulting in derived time-series of 2- and 20-year return period low flows (sampling uncertainty on return period estimates is not considered). To investigate (potentially non-linear) trends in the derived time-series of low flow return levels for the OBS run, isotonic regression (Barlow et al. 1972) is applied. This involves fitting the best non-decreasing or non-increasing stepfunction, with the standard deviation (x2) of the step-function used as a measure of trend size (signed to represent trend direction). For the HIST ensemble runs, the isotonic regression is applied to the $10^{\text {th }}, 25^{\text {th }}, 50^{\text {th }}, 75^{\text {th }}$ and $90^{\text {th }}$ percentiles of the 2 - and 20 -year return period low flows estimated for each ensemble member separately. To assess trend significance, the above analysis is repeated 500 times on random permutations of AMIN. If the original trend size sits in the lowest or highest $5 \%$ of the distribution of trend sizes from the permutations, then it is significant at the $10 \%$ level (in a two-sided test). A similar moving window approach with isotonic regression was applied by Kay and Jones (2012) and Kay and Crooks (2014) for flood frequency trends.

The time-periods covered by the Baseline, Near-Future and Far-Future ensemble runs (1975-2004, 2020-2049, 2070-2099 respectively) are too short to allow trend analysis, so low flow frequency curves are simply fitted to 28 years of AMIN data for each point for each run (the first two years of each run are again neglected). The analysis then looks at percentage changes in median 2- and 20year return period low flows from the Baseline time-period to the Near-Future and Far-Future timeperiods. Ideally more AMIN would be used for low flow frequency analysis; Zaidman et al. (2002) recommend using at least 40 years of data and say it is inadvisable to use fewer than 25 years. Only 28 years could be used for each Near-Future and Far-Future time-series, hence very high return period low flows cannot be analysed, but the assumption of stationarity of annual minima is less of an issue for this shorter time-period than for a longer time-period.

Results are presented as national maps, showing all points in Great Britain with a cumulative catchment area greater than $50 \mathrm{~km}^{2}$. To aid understanding, specific results are also shown for four example catchments across the country; the Ruchill Water at Cultybraggan, the Ure at Westwick Lock, the Trent at Colwick and the Thames at Kingston (Figure 1 and Supp. Section 1).

\section{Results}

\subsection{Historical trend analysis}

Figure 2 shows the 7- and 30-day AMIN and associated transient low flows simulated by the OBS run for the four example catchments, and Table 1 shows the associated trends in low flow frequency and their significance. Neither the Trent nor the Thames shows any significant trend, even at the $10 \%$ level. The Ure only shows a significant (negative) trend in 2-year return period low flows of 7-and 30-day duration (significant at the $5 \%$ level). The Ruchill Water shows significant (negative) trends in the 2 - and 20-year return period low flows at the 7-day duration, and 2-year return period low flows at the 30 -day duration (significant at the $5 \%$ level).

Figure 2 also shows the median and range of transient low flows simulated by the HIST ensemble runs for the four example catchments. In this case, none of the illustrated percentiles $\left(5^{\text {th }}, 25^{\text {th }}, 50^{\text {th }}\right.$, 
$75^{\text {th }}, 95^{\text {th }}$ ) shows a trend significant at the $10 \%$ level (although individual ensemble members may show trends, see later); the $50^{\text {th }}$ percentile trends are given in Table 1 . When comparing low flows from the HIST ensemble runs with those from the OBS run, the former tend to be below to the latter. Possible reasons for this include some over-estimation of PE by the climate model (Guillod et al. 2018 Figure 4), or issues with the relatively coarse spatial scale of the climate model precipitation and its bias-correction.

Table 1 Modelled trends in low flow frequency at the 2- and 20-year return period, for 7- and 30day durations, for the four example catchments. The significance of each trend is shown beneath it (see key below table).

\begin{tabular}{|c|c|c|c|c|c|c|}
\hline Run & Duration & Return period & Ruchill Water & Ure & Trent & Thames \\
\hline \multirow[t]{7}{*}{ OBS } & 7-day & 2-year & -0.095 & -0.188 & 0.781 & -1.991 \\
\hline & & & ** & ** & - & - \\
\hline & & 20-year & -0.050 & -0.049 & -0.992 & -1.472 \\
\hline & & & ** & - & - & - \\
\hline & 30-day & 2-year & -0.206 & -0.519 & 1.362 & -2.065 \\
\hline & & & $* *$ & $* *$ & - & \\
\hline & & 20-year & -0.078 & 0.078 & -0.816 & -1.316 \\
\hline \multirow{7}{*}{$\begin{array}{l}\text { HIST } \\
\text { (median) }\end{array}$} & 7-day & 2-year & -0.009 & -0.017 & -0.303 & -0.566 \\
\hline & & & - & - & - & - \\
\hline & & 20-year & 0.003 & 0.008 & 0.061 & -0.366 \\
\hline & & & - & - & - & - \\
\hline & 30-day & 2-year & -0.015 & -0.044 & -0.547 & -0.679 \\
\hline & & & - & - & - & \\
\hline & & 20-year & 0.008 & 0.018 & 0.118 & -0.300 \\
\hline
\end{tabular}

*** significant at $1 \%$ level; ${ }^{* *}$ significant at $5 \%$ level; * significant at $10 \%$ level; - not significant

Maps of low flow trends from the OBS run (standardised by dividing by the 2-year return period low flow magnitude for the last position of the moving window) show that they are generally only significant in parts of Scotland and northern England, plus some parts of eastern England and Wales (Figure 3). The majority of significant trends are negative (i.e. lower low flows), although there are a small number of points with significant positive trends in 2-year return period low flows in central England (including parts of the Trent catchment). Most of the significant trends in low flows come from trends in the GEV location parameter, rather than the scale or shape parameters (Supp. Section 2.1); a decrease in the location parameter has the effect of shifting the whole low flow frequency curve downwards. Maps of trends for the HIST ensemble runs show substantially fewer significant trends than the OBS run, whether for the median or for high or low percentiles (not shown). Even if the trend analysis is applied to each HIST ensemble run separately (rather than to percentiles), the majority of ensemble members show no significant (positive or negative) trends (Supp. Section 2.2).

\subsection{Future change analysis}

Figure 4 shows the medians and ranges of the 7- and 30-day low flow frequency curves simulated by the Baseline, Near-Future and Far-Future ensembles (the latter two using adjusted $r_{s}$ PE; NF_adjrs and FF_adjrs), for the four example catchments. There is a reduction in low flows in the future in all cases, with a greater reduction for the later time-period. The ensemble ranges are not very wide and do not overlap much, except at higher return periods (above 10 -years) when there in any case greater uncertainty in fitting the GEV to the AMIN (due to using only 28 years). Figure 4 also shows the low flow frequency curve simulated by the OBS run for 1971-2000. As in Figure 2, there is a tendency for the low flows from the Baseline ensemble runs to be below those from the OBS run. 
This is particularly the case for the Ruchill catchment, which could be related to its small size $\left(100 \mathrm{~km}^{2}\right)$ relative to the climate model grid scale $(\sim 25 \mathrm{~km})$.

Maps of the percentage change in 2- and 20-year return period 7-day duration low flows, between the Baseline median and the Near-Future and Far-Future (NF_adjrs and FF_adjrs) medians, show reductions across the country (Figure 5). Reductions are generally larger in the south than the north, larger at the 20-year return period than the 2-year return period, and larger for the later timeperiod. Similar reductions are seen for 30-day duration low flows (Supp. Figure S3).

Figure 4 also shows the medians of the 7- and 30-day low flow frequency curves simulated by the Near-Future and Far-Future ensembles with fixed $r_{s}$ PE (NF_fixrs and FF_fixrs) for the four example catchments. Comparing these to the equivalent medians with adjusted $r_{s}$ PE (NF_adjrs and FF_adjrs) shows that using a PE calculation that accounts for changes in stomatal resistance moderates the decreases in low flows, particularly for the later time-period.

This is also shown by the maps in Figure 6 , which present the ratios of the percentage changes in 2and 20-year return period 7-day duration low flows when using adjusted $r_{s}$ PE compared to using fixed $r_{s}$ PE. Almost all of the ratios are less than one, meaning that there is less of a decrease in low flows when using PE with adjusted $r_{s}$ than fixed $r_{s}$. The differences in percentage changes are much greater for the later time-period, although there is significant spatial variation, with the greatest differences in parts of eastern Scotland, north-east England and southern England. Similar ratio patterns are seen for 30-day duration low flows (Supp. Figure S4). Note that use of a high emissions scenario (RCP 8.5) accentuates differences for the later time-period; under a lower emissions scenario the adjustment to $r_{s}$ values would be less.

\section{Discussion and Conclusions}

A national-scale hydrological model has been applied with climate data representing both past and future time-periods, to investigate historical trends and potential future changes in low flow frequency. The results for the past time-period show relatively few significant trends in historical low flows, whether at the 2- or 20-year return period and whether based on 7-day or 30-day annual minima. The significant negative trends seen in some parts of Scotland, northern and eastern England, and Wales when using observation-based data are generally not seen when using climate model data. However, the results using climate model data for future time-periods show reductions in low flows, which are generally larger in the south of the country, at the higher (20-year) return period, and for the later (far-future) time-period. Flow reductions are more limited if the estimates of future potential evaporation include the effect of increased carbon dioxide concentrations on stomatal resistance.

The relative lack of historical trends in low flows is consistent with analyses of observed flows, which generally show few clear trends in low flow indices in Britain (Hannaford and Marsh 2006) or for sets of catchments in northern Europe (Hannaford et al. 2013). Similarly, analysis of drought characteristics derived from simulated flows across Britain showed no clear changes through time (Rudd et al. 2017). One advantage of using a hydrological model for such analyses is that the simulated flows are typically only affected by changes in the climatic inputs, whereas gauged flows can be affected by other factors that can change through time, like abstractions, channel modification, land-use etc. (Hannaford 2015). Also, gauged flow records are typically relatively short so trends can be difficult to distinguish from natural variability (Hannaford 2015). The availability of much longer climate records means that simulated flows can be produced for longer periods, and in a consistent way for a large number of catchments (or on a grid, as here); although the climate timeseries may not be completely consistent through time due to changes in measurement networks and methods (Keller et al. 2015). A similar modelling approach was taken for catchments in France (Caillouet et al. 2017), using probabilistic reconstructed climate data to drive a hydrological model for 1871-2012. 
For the long observation-based run of the hydrological model (1891-2015), only daily precipitation and monthly temperature data were available for the full period, thus PE had to be estimated solely from temperature rather than using a more physically-based scheme like Penman-Monteith which includes other climate variables and therefore could have different temporal changes (Kay et al. 2013). The Penman-Monteith scheme was however used to produce PE for the climate model ensembles (without bias-correction), so this could be one reason for the difference in trend results between the observation-based run and the historical ensemble runs (Section 3.1). For example, Dewes et al. (2017) showed that use of different PE schemes leads to different trends in standardised drought indices in the US. Another possible reason for the difference in trend results here could be the application to percentiles from the historical ensemble runs, as this is likely to smooth the effects of natural variability (thus making the analysis more robust), whereas the presence of natural variability is likely to affect analysis of the observation-based run. Indeed, application of the trend analysis to individual historical ensemble members showed small numbers with significant trends, both positive and negative, in some parts of the country, but predominantly showed few significant trends.

The use of (past and future) climate ensembles is particularly important when looking at low flows and droughts as it greatly increases the sample size; the most serious droughts in Britain tend to be prolonged in time and coherent in space, so the limited historical record may not provide a good basis for future planning (Watts et al. 2015). However, the results presented here only look at the effect of changes in climate, whereas changes in a number of other factors, like land-use, will be important. For example, an analysis of simulated river flows for the Thames at Kingston (1891-2013) suggests that the increase in urban land-cover in that period has increased summer flows by around $15 \%$, due to runoff from urban areas occurring even when soil moisture deficits exist (Crooks and Kay 2015). Similarly, the fact that the hydrological model does not include abstractions/discharges could be an issue, since water managers need to know what is happening, or could happen in the future, to real river flows rather than hypothetical 'natural' flows. Ongoing work aims to enhance G2G by including surface and groundwater abstractions/discharges.

The results presented here for future changes in low flows in Britain are based on a single GCM with a single nested RCM (albeit with sea-surface temperature changes derived from a number of other GCMs; Section 2.2); results using other GCMs could be different. For example, Sperna Weiland et al. (2012) show that projections from a global hydrological model driven by data from $12 \mathrm{GCMs}$ can diverge widely, with less consistency for changes in minimum and maximum flow than mean flow. Similarly, only one hydrological model has been applied here. A number of studies have shown that GCM uncertainty is greater than hydrological model uncertainty (e.g. Kay et al. 2009, Gosling et al. 2011), but other studies have shown that hydrological model uncertainty can be greater for low flows than for mean or high flows (Vetter et al. 2017, Giuntoli et al. 2015). Similarly, Seiller et al. (2017) showed that the choice of both the hydrological model and the objective function used for calibration can significantly alter the projected changes in low flow, thus the choice of hydrological model may be more important for drought analyses. Another factor not considered here is snow, due to limited availability of required temperature data. While the effect of snow on future changes in low flows in Britain is likely to be limited (even more so than for high flows; Bell et al. 2016), and restricted to small parts of the Scottish Highlands for example, its historical effect could have been greater as temperatures were lower and thus snow would have been more widespread and prolonged (Kay 2016). Ongoing work is investigating use of data from an RCM driven by boundary conditions from 20CR reanalysis (Compo et al. 2011) for 1851-2014, to look the effects of changes in snow on historical changes in low flows across Britain.

From a water management perspective, anthropogenic climate change is only one of many stressors on sustainability of water resources. Non-climatic factors like population increase and economic development can place further strain on water resources by increasing water demand, alongside potential decreases in water supply caused by both climatic and non-climatic factors (Jiménez 
Cisneros et al. 2014). Studies investigating the potential future balance of supply and demand, like that of Arnell and Lloyd-Hughes (2014) based on a simple threshold of annual per capita water availability, are thus important, as is more detailed water resource system modelling (Borgomeo et al. 2016). The flows from the hydrological modelling described here are also being used to investigate potential future impacts on river ecology and agricultural production.

\section{Acknowledgements}

This study is an outcome of MaRIUS: MAnaging the Risks, Impacts and Uncertainties of droughts and water Scarcity, funded by the UK Natural Environment Research Council's Drought and Water Scarcity programme (NE/L010208/1). We thank the Met Office National Climate Information Centre (for the $5 \mathrm{~km}$ temperature data) and two anonymous reviewers.

\section{References}

Arnell NW, Lloyd-Hughes B (2014). The global-scale impacts of climate change on water resources and flooding under new climate and socio-economic scenarios. Clim. Chang., 122, 127-140.

Barlow RE, Bartholomew DJ et al. (1972). Statistical inference under order restrictions; the theory and application of isotonic regression. Wiley: New York.

Bell VA, Davies HN et al. (2013). Developing a large-scale water-balance approach to seasonal forecasting: application to the 2012 drought in Britain. Hydrol. Process., 27(20), 3003-3012.

Bell VA, Kay AL et al. (2012). How might climate change affect river flows across the Thames Basin? An area-wide analysis using the UKCP09 Regional Climate Model ensemble. J. Hydrol. 442-443, 89104.

Bell VA, Kay AL et al. (2016). An assessment of the possible impacts of climate change on snow and peak river flows across Britain. Clim. Chang., 136(3), 539-553.

Bell VA, Kay AL et al. (2007). Development of a high resolution grid-based river flow model for use with regional climate model output. Hydrol. Earth Syst. Sci., 11(1), 532-549.

Bell VA, Kay AL et al. (2009). Use of soil data in a grid-based hydrological model to estimate spatial variation in changing flood risk across the UK. J. Hydrol., 377(3-4), 335-350.

Borgomeo E, Mortazavi-Naeini $\mathrm{M}$ et al. (2016). Trading-off tolerable risk with climate change adaptation costs in water supply systems. Water Resour. Res., 52(2), 622-643.

Caillouet L, Vidal J-P et al. (2017). Ensemble reconstruction of spatio-temporal extreme low-flow events in France since 1871. Hydrol. Earth Syst. Sci., 21(6), 2923-2951.

Charlton MB, Arnell NW (2014). Assessing the impacts of climate change on river flows in England using the UKCP09 climate change projections. J. Hydrol., 519, 1723-1738.

Christierson BV, Vidal J-P, Wade SJ (2012). Using UKCP09 probabilistic climate information for UK water resource planning. J. Hydrol., 424-425, 48-67.

Compo GP, Whitaker JS et al. (2011). The Twentieth Century Reanalysis Project. Q. J. Royal Meteorol. Soc., 137(654), 1-28.

Crooks SM, Kay AL (2015). Simulation of river flow in the Thames over 120 years: Evidence of change in rainfall-runoff response? J. Hydrol.: Regional Studies, 4, 172-195.

Dai A (2013). Increasing drought under global warming in observations and models. Nature Climate Change, 3, 52-58.

Dewes CF, Rangwala I et al. (2017). Drought risk assessment under climate change is sensitive to methodological choices for the estimation of evaporative demand. PLOS ONE, 12(3).

Gosling SN, Taylor RG et al. (2011). A comparative analysis of projected impacts of climate change on river runoff from global and catchment-scale hydrological models. Hydrol. Earth Sys. Sci., 15, 279294. 
Guillod BP, Jones RG et al. (2017). weather@home 2: validation of an improved global-regional climate modelling system. Geosci. Model Dev., 10, 1849-1872.

Guillod BP, Jones RG et al. (2018). A large set of potential past, present and future hydrometeorological time series for the UK. Hydrol. Earth Syst. Sci., 22, 611-634, doi:10.5194/hess-22611-2018.

Giuntoli I, Vidal J-P et al. (2015). Future hydrological extremes: the uncertainty from multiple global climate and global hydrological models. Earth System Dynamics, 6(1), 267-285.

Hannaford J (2015). Climate-driven changes in UK river flows: A review of the evidence. Prog. Phys. Geogr., 39(1), 29-48.

Hannaford J, Buys $\mathrm{G}$ et al. (2013). The influence of decadal-scale variability on trends in long European streamflow records. Hydrol. Earth Syst. Sci., 17(7), 2717-2733.

Hannaford J, Marsh T (2006). An assessment of trends in UK runoff and low flows using a network of undisturbed catchments. Int. J. Climatol., 26(9), 1237-1253.

Hough M, Jones RJA (1997). The United Kingdom Meteorological Office rainfall and evaporation calculation system: MORECS version 2.0- an overview. Hydrol. Earth Syst. Sci., 1(2), 227-239.

Jiménez Cisneros BE, Oki T et al. (2014). Freshwater resources. In: Climate Change 2014: Impacts, Adaptation and Vulnerability. Part A: Global and Sectoral Aspects. Contribution of Working Group II to the Fifth Assessment Report of the IPCC [Field CB et al. (eds)]. Cambridge University Press, pp.229269.

Kay AL (2016). A review of snow in Britain: the historical picture and future projections. Prog. Phys. Geogr., 40(5), 676-698.

Kay AL, Bell VA, Blyth EM et al. (2013). A hydrological perspective on evaporation: historical trends and future projections in Britain. J. Water Clim. Change, 4(3), 193-208.

Kay AL, Crooks SM (2014). An investigation of the effect of transient climate change on snowmelt, flood frequency and timing in northern Britain. Int. J. Climatol., 34(12), 3368-3381.

Kay AL, Davies HN et al. (2009). Comparison of uncertainty sources for climate change impacts: flood frequency in England. Clim. Chang., 92(1-2), 41-63.

Kay AL, Jones DA (2012). Transient changes in flood frequency and timing in Britain under potential projections of climate change. Int. J. Climatol., 32(4), 489-502.

Kendon M, Marsh T, Parry S (2013). The 2010-2012 drought in England and Wales. Weather, 68(4), 88-95.

Keller VDJ, Tanguy M et al. (2015). CEH-GEAR: $1 \mathrm{~km}$ resolution daily and monthly areal rainfall estimates for the UK for hydrological and other applications. Earth Syst. Sci. Data, 7, 143-155.

Massey N, Jones R et al. (2015). weather@home - development and validation of a very large ensemble modelling system for probabilistic event attribution, Quart. J. Roy. Meteor. Soc., 141, 1528-1545.

Maxey R, Cranston M et al. (2012). The use of deterministic and probabilistic forecasting in countrywide flood guidance in Scotland, in: BHS Eleventh National Symposium, Hydrology for a Changing World, pp.01-07, doi:10.7558/bhs.2012.ns33

Monteith JL (1965). Evaporation and environment. Symp. Soc. Exp. Biol., 19, 205-234.

Murphy JM, Sexton DMH et al. (2009). UK Climate Projections Science Report: Climate change projections. Met Office Hadley Centre, Exeter, UK.

Oudin L, Hervieu F et al. (2005). Which potential evapotranspiration input for a lumped rainfallrunoff model? Part 2 - Towards a simple and efficient potential evapotranspiration model for rainfall-runoff modelling. J. Hydrol., 303, 290-306.

Price D, Hudson K et al. (2012). Operational use of a grid-based model for flood forecasting, in: Proceedings of the ICE, Water Management, 65-77. 
Prudhomme C, Giuntoli I et al. (2014). Hydrological droughts in the 21st century, hotspots and uncertainties from a global multimodel ensemble experiment. PNAS, 111, 3262-3267.

Prudhomme C, Young A et al. (2012). The drying up of Britain? A national estimate of changes in seasonal river flows from 11 Regional Climate Model simulations. Hydrol. Process., 26(7), 11151118.

Riahi K, Rao S et al. (2011). RCP 8.5-A scenario of comparatively high greenhouse gas emissions. Clim. Chang., 109, 33-57.

Roudier P, Andersson JCM et al. (2016). Projections of future floods and hydrological droughts in Europe under $\mathrm{a}+2^{\circ} \mathrm{C}$ global warming. Clim. Chang., 135, 341-355.

Rudd AC, Bell VA, Kay AL (2017). National-scale analysis of simulated hydrological droughts (18912015). J. Hydrol., 550, 368-385.

Rudd AC, Kay AL (2016). Use of very high resolution climate model data for hydrological modelling: estimation of potential evaporation. Hydrol. Res., 47(3), 660-670.

Seiller G, Roy R, Anctil F (2017). Influence of three common calibration metrics on the diagnosis of climate change impacts on water resources. J. Hydrol., 547, 280-295.

Sheffield J, Wood EF, Roderick ML (2012). Little change in global drought over the past 60 years. Nature, 491, 435-438.

Soulsby C, Helliwell RC et al. (1997). Seasonal snowpack influence on the hydrology of a sub-arctic catchment in Scotland. J. Hydrol., 192, 17-32.

Sperna Weiland FC, van Bewek LPH et al. (2012). Global patterns of change in discharge regimes for 2100. Hydrol. Earth Sys. Sci., 16, 1047-1062.

Svensson C, Kundzewicz ZW, Maurer T (2005). Trend detection in river flow series: 2. Flood and lowflow index series. Hydrological Sciences Journal, 50(5), 811-824.

Tanguy M, Dixon H et al. (2016). Gridded estimates of daily and monthly areal rainfall for the United Kingdom (1890-2015) [CEH-GEAR]. NERC Environmental Information Data Centre. doi:10.5285/33604ea0-c238-4488-813d-0ad9ab7c51ca.

Trenberth KE, Dai A et al. (2014). Global warming and changes in drought. Nature Climate Change, 4(1), 17-22.

Van Lanen HAJ, Laaha G et al. (2016). Hydrology needed to manage droughts: the 2015 European case. Hydrol. Process. 30, 3097-3104.

Vetter T, Reinhardt J et al. (2017). Evaluation of sources of uncertainty in projected hydrological changes under climate change in 12 large-scale river basins. Clim. Chang., 141, 419-433.

Watts G, Battarbee RW et al. (2015). Climate change and water in the UK - past changes and future prospects. Prog. Phys. Geogr., 39, 6-28.

Zaidman MD, Keller V, Young AR (2002). Low flow frequency analysis: Guidelines for best practice. R\&D Technical Report W6-064/TR1, Environment Agency, Bristol. 
Figures

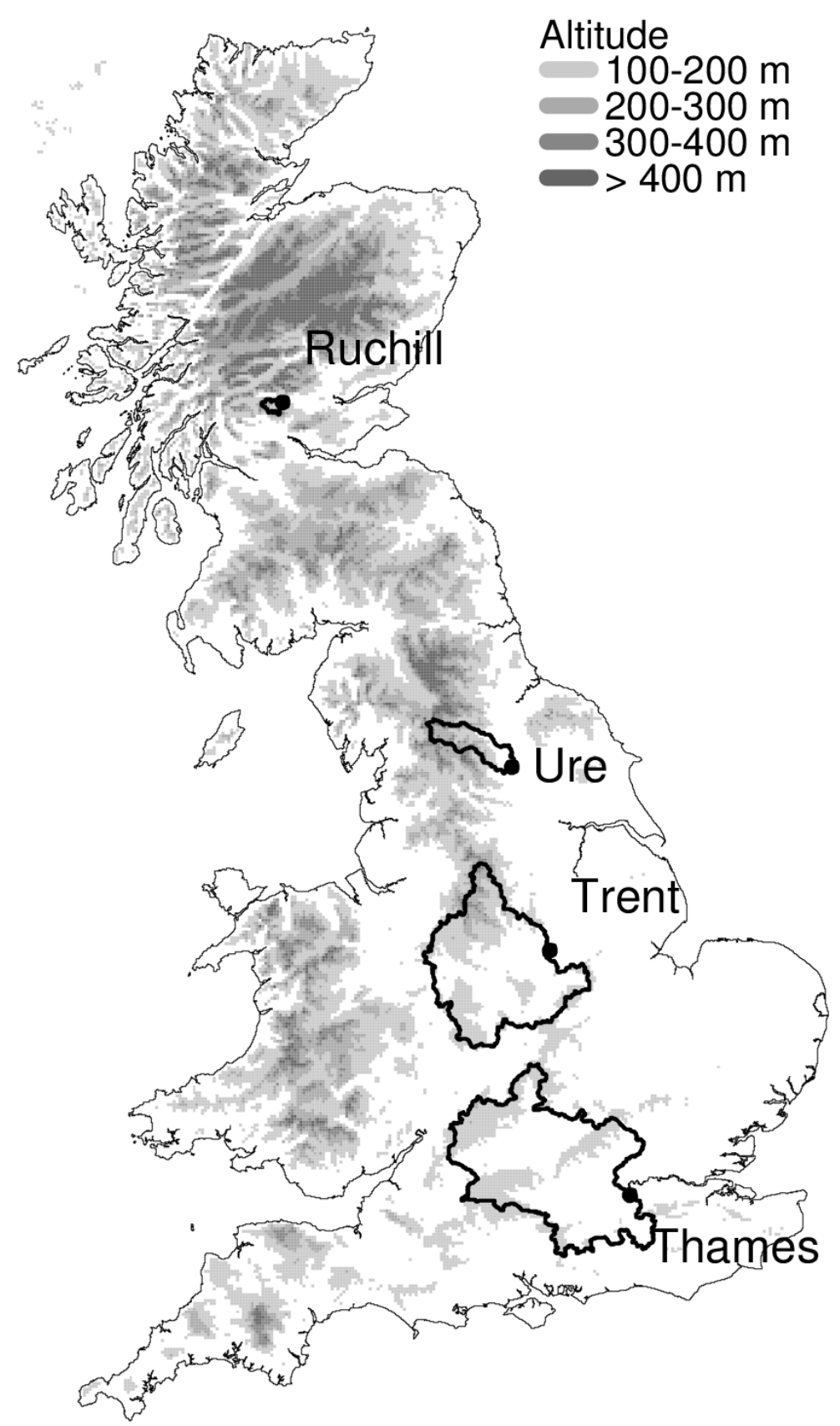

Figure 1 Locations of the four example catchments. 

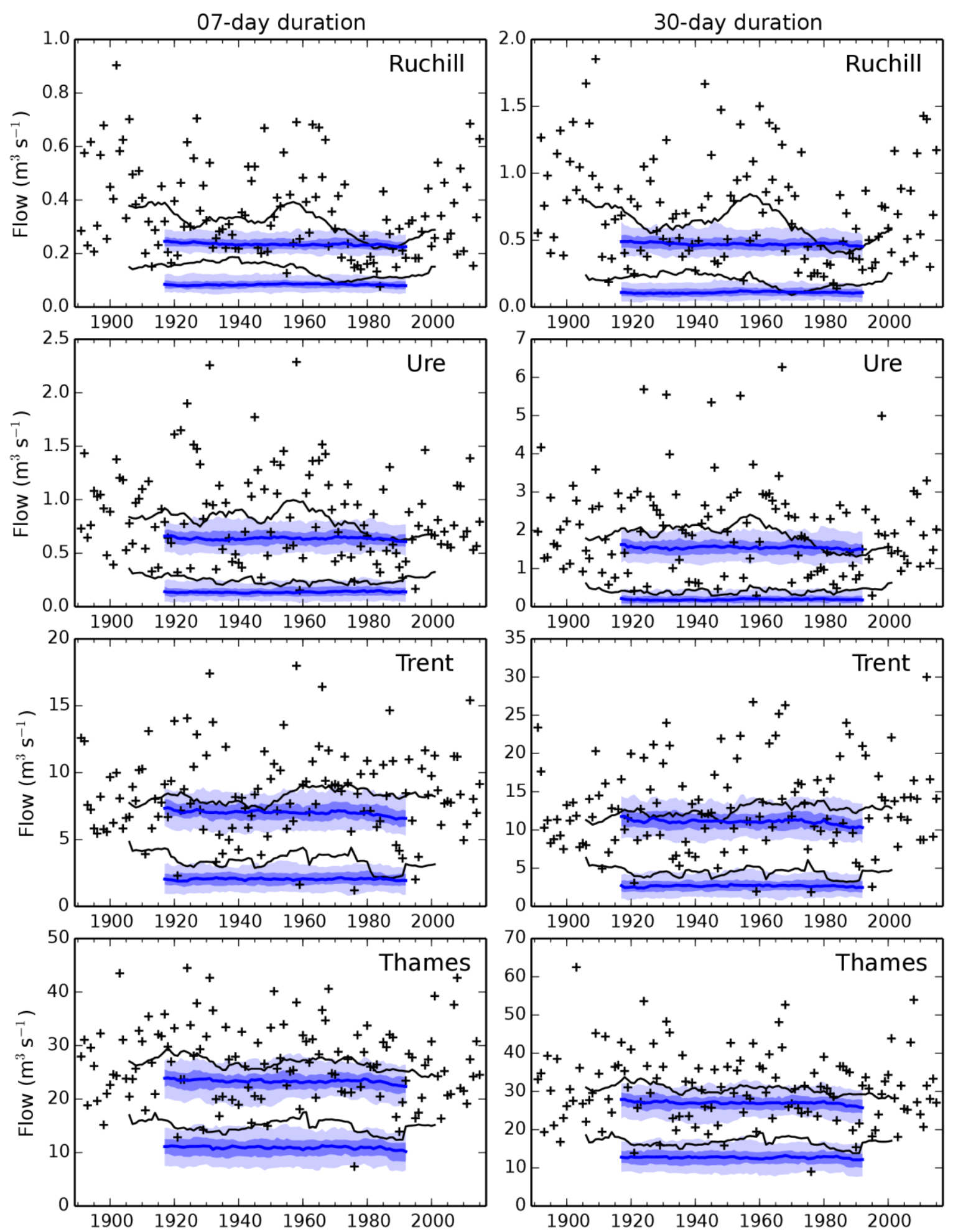

Figure 2 AMIN (plus signs) and transient low flows at the 2- and 20-year return period (black lines), for 7- and 30-day durations (left and right), simulated by the OBS run for four example catchments. Also shown are the medians of the transient low flows at the 2- and 20-year return period simulated by the HIST ensemble runs (blue lines), with the $25^{\text {th }}-75^{\text {th }}$ and $5^{\text {th }}-95^{\text {th }}$ percentile ranges (dark and light blue shading). 

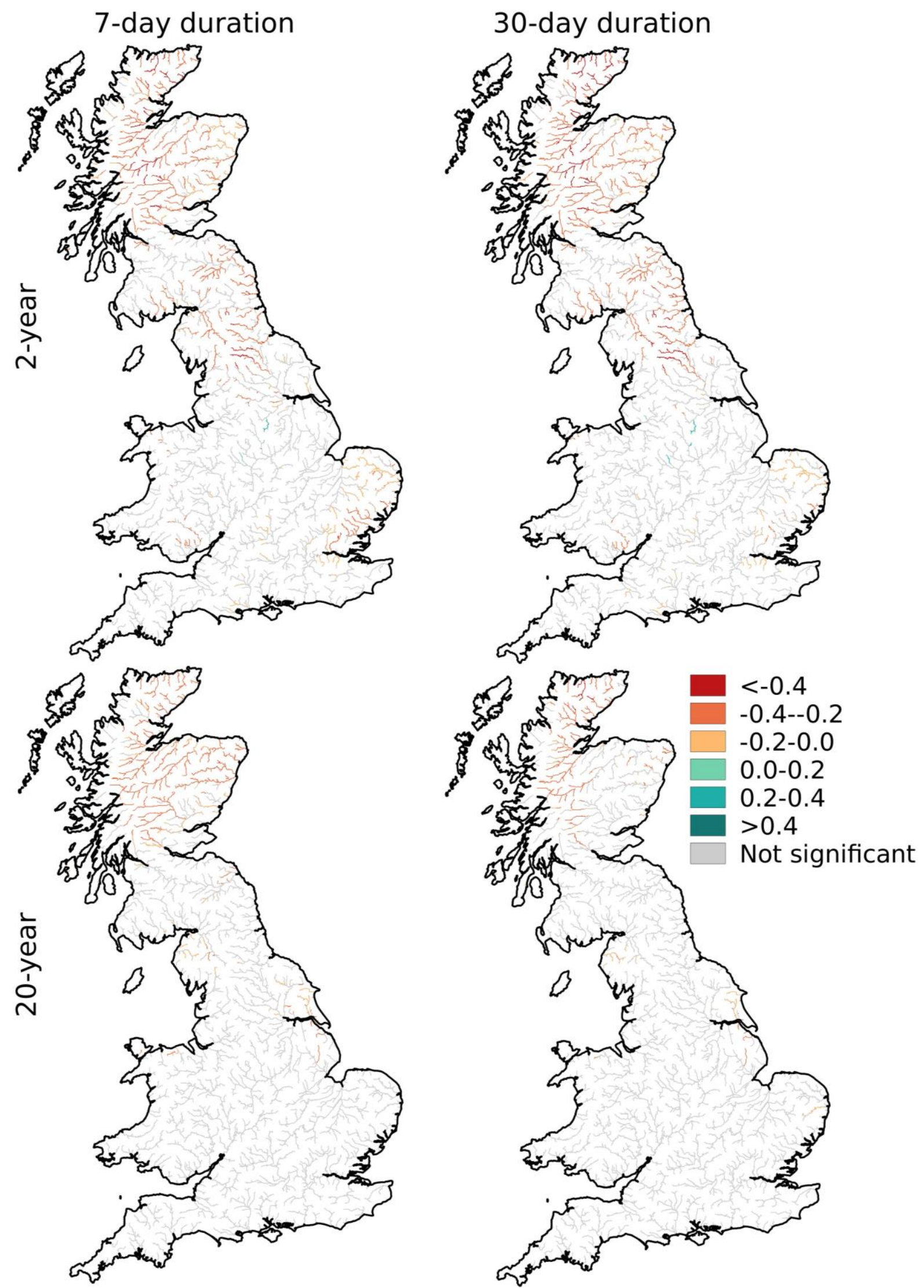

Figure 3 Maps of trends from the OBS run (scaled by the 2-year return period low flow magnitude from the last position of the moving window), for 2-and 20-year return period low flows of 7- and 30 -day duration. Trends that are not significant at the $10 \%$ level are greyed out. 

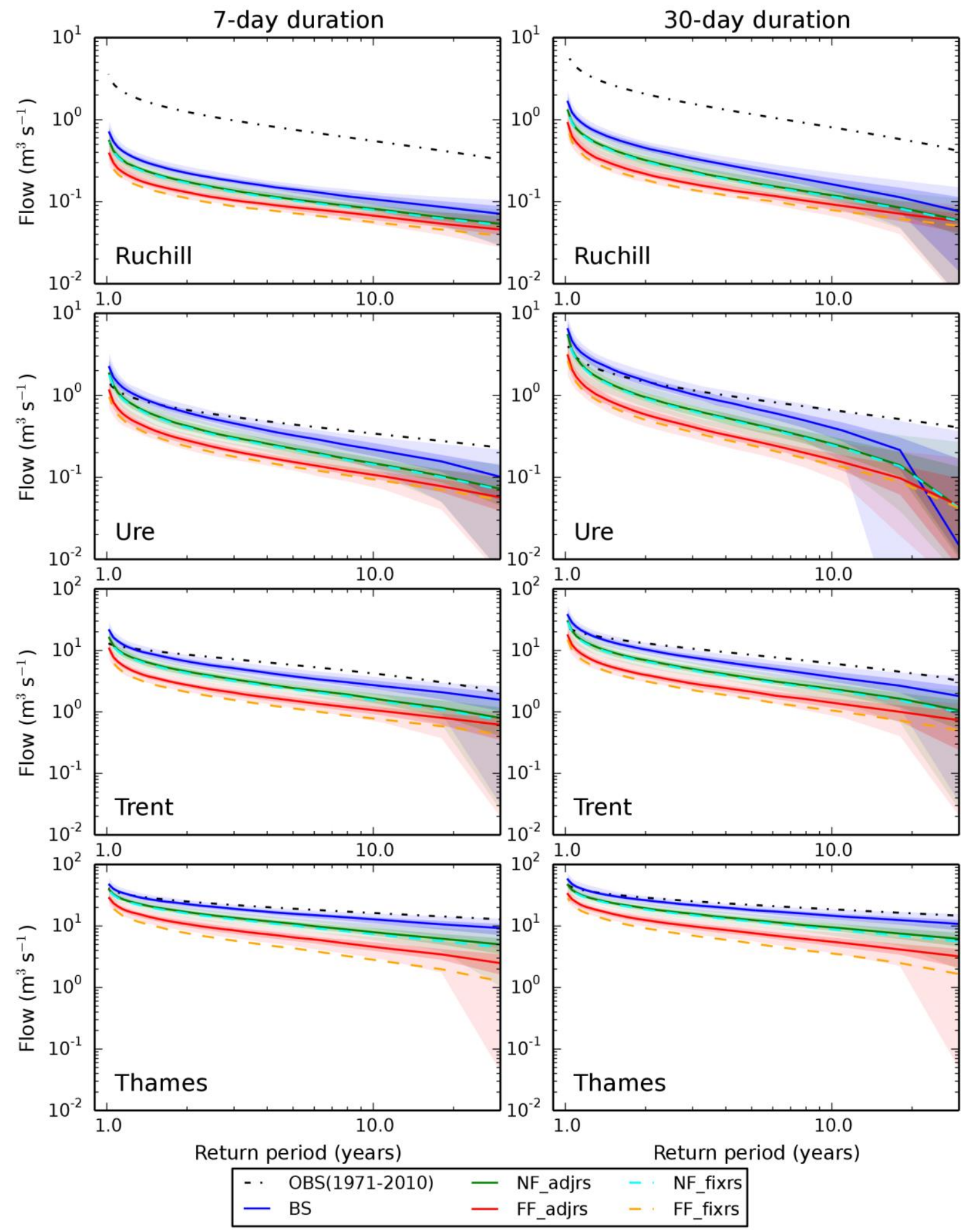

Figure 4 Low flow frequency curve medians (lines) and ranges (shading) for the four example catchments, at the 7-day and 30-day durations (left and right). The medians are shown for five ensembles; Baseline (BS), Near-Future and Far-Future with adjusted $r_{s}$ PE (NF_adjrs, FF_adjrs), and Near-Future and Far-Future with fixed $r_{s}$ PE (NF_fixrs, FF_fixrs). The $25^{\text {th }}-75^{\text {th }}$ and $5^{\text {th }}-95^{\text {th }}$ percentile ranges (dark and light shading) are only shown for the $\mathbf{B S}, \mathbf{N F}$ _adjrs and FF_adjrs ensembles. Also shown is the low flow frequency curve simulated by the OBS run. 

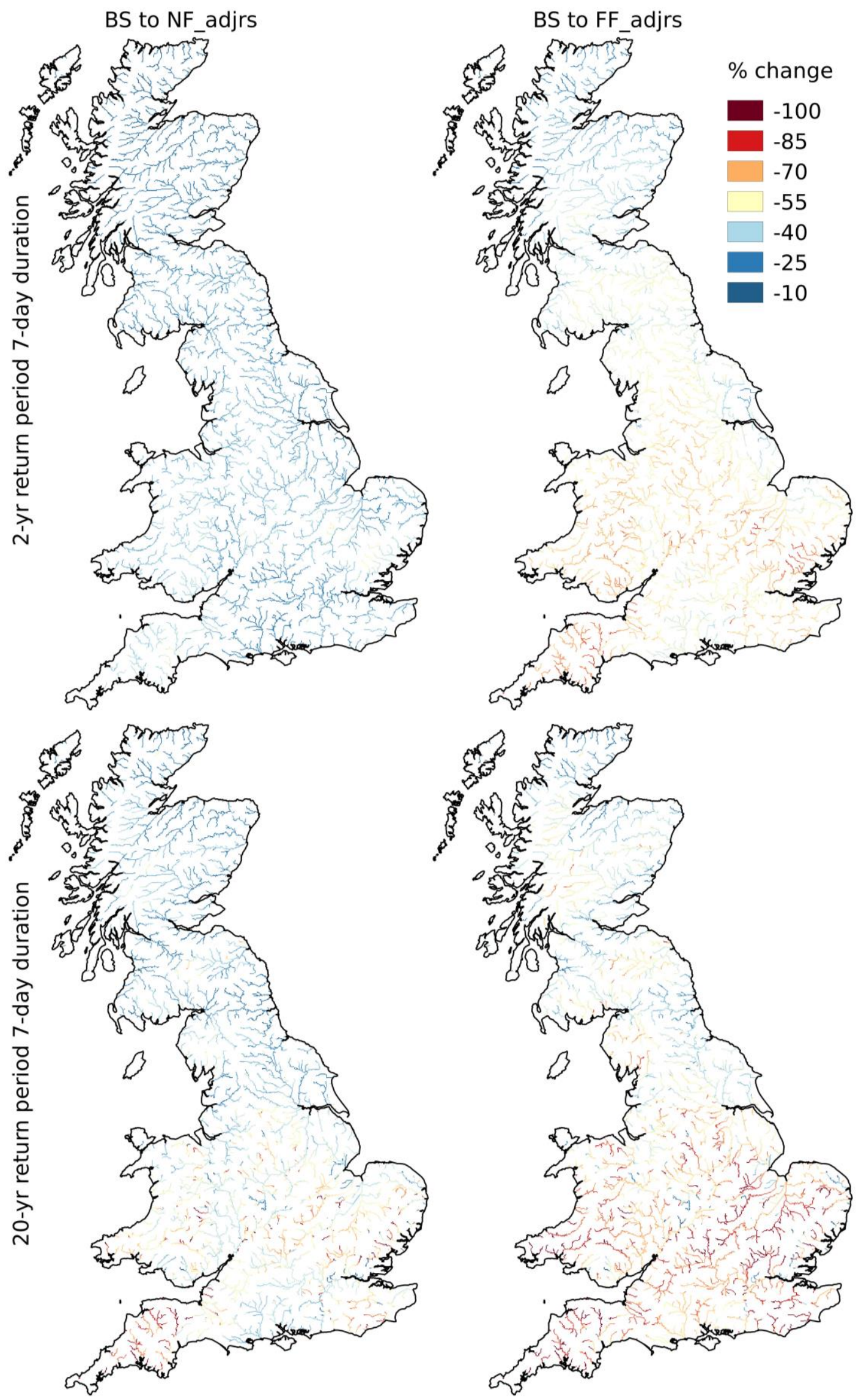

Figure 5 Maps of the percentage change in 2- and 20-year return period 7-day duration low flows, between the Baseline (BS) ensemble median and the Near-Future and Far-Future ensemble medians with adjusted $r_{s}$ PE (NF_adjrs and FF_adjrs; left and right respectively). 

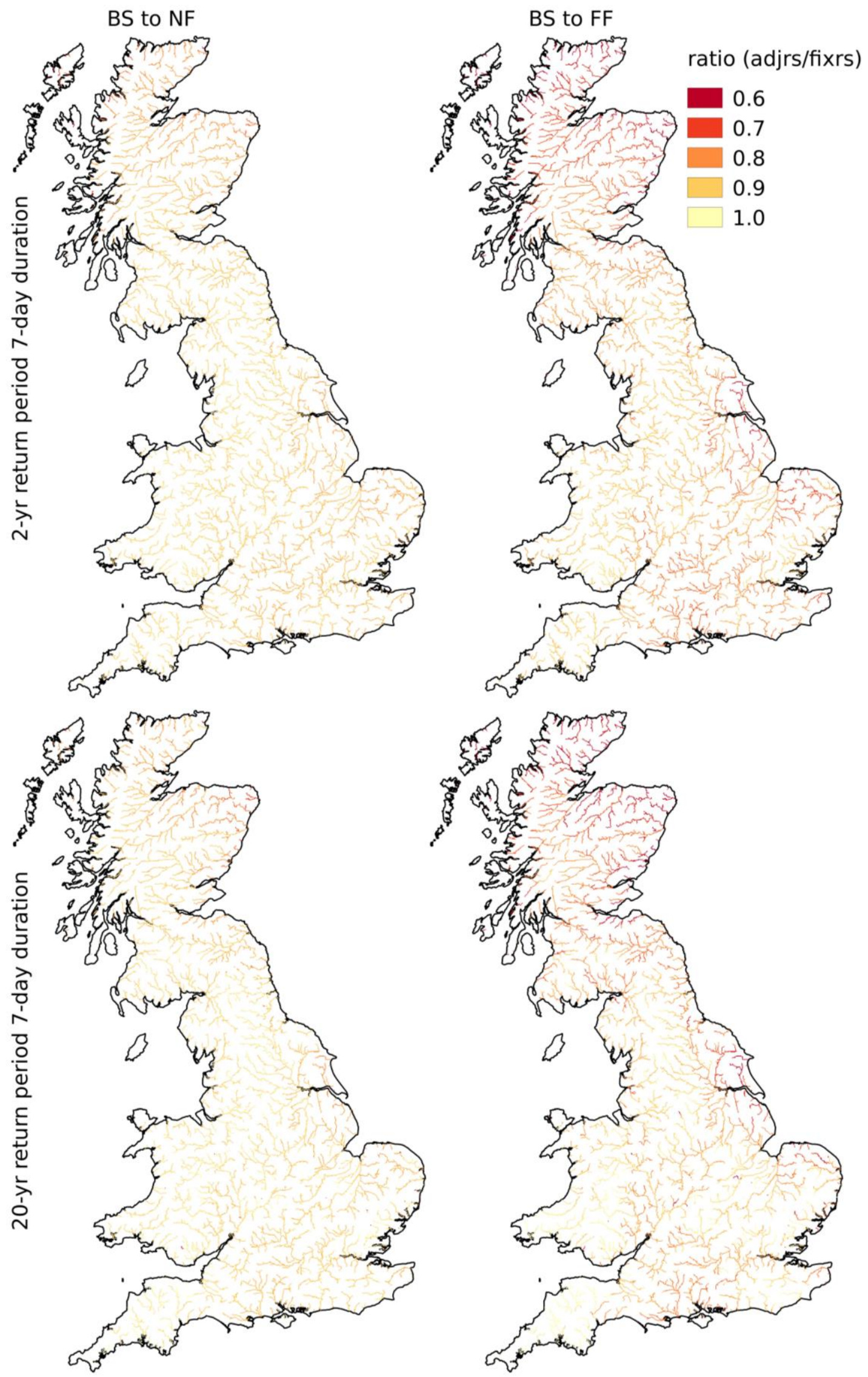

Figure 6 Maps showing the ratios of the percentage changes in low flows when using adjusted and fixed $r_{s}$ PE for Near-Future and Far-Future (left, NF_adjrs/NF_fixrs; right, FF_adjrs/FF_fixrs), for 2and 20-year return period 7-day duration low flows. 


\section{National-scale analysis of low flow frequency: historical trends and potential future changes}

Kay A.L., Bell V.A., Guillod B.P., Jones R.G., Rudd A.C.

\section{Supplementary Material}

\section{Example catchments}

Results are mainly presented as national maps, but to aid understanding specific results are also shown for four example catchments. Some catchment information is provided in Table S1.

Table S1 Details of the four example catchments.

\begin{tabular}{lllrr}
\hline River & Location & NRFA* station number & Area $\left(\mathrm{km}^{2}\right)$ & $\mathrm{SAAR}_{61-90} * *(\mathrm{~mm})$ \\
\hline Ruchill Water & Cultybraggan & 16003 & 99.5 & 1889 \\
Ure & Westwick Lock & 27007 & 914.6 & 1118 \\
Trent & Colwick & 28009 & 7486 & 761 \\
Thames & Kingston & 39001 & 9948 & 706 \\
\hline
\end{tabular}

*National River Flow Archive; nrfa.ceh.ac.uk **Standard Average Annual Rainfall for 1961-1990

\section{Results}

\subsection{Historical trend analysis: GEV parameters}

The generalised extreme value (GEV) distribution has three parameters - location $\xi$, scale $\alpha$ and shape $k$ - and the low flow $Q_{T}$ with a return period of $T$ years is given by

$$
Q_{T}=\xi+(\alpha / k)\left(1-(\ln T)^{k}\right) \quad(k \neq 0) .
$$

An increase in the location parameter $\xi$ has the effect of shifting the whole low flow frequency curve upwards, while an increase in the scale parameter $\alpha$ causes an increase in lower return period low flows and a decrease in higher return period low flows (with no change for low flows of return period $T=e)$. An increase in the shape parameter $k$ causes a decrease in low flows of all return periods except $T=e$.

Figure S1 presents maps of the trends in the GEV parameters from the OBS run, showing significant negative trends in the location parameter in some parts of the country, but few significant trends in either the scale or shape parameters anywhere in the country.

\subsection{Historical trend analysis: HIST ensemble runs}

Figure S2 presents the proportion of HIST ensemble runs showing positive (left) or negative (right) trends (significant at the $10 \%$ level) in 2- and 20 -year return period 7 -day duration low flows. At the 2 -year return period, at most $23 \%$ of ensemble members show significant positive trends and at most $27 \%$ show significant negative trends, so at least $50 \%$ (usually much more) show no significant trend in any one location. At the 20-year return period the equivalent figures are at most $15 \%$ positive and $15 \%$ negative, so at least $70 \%$ show no significant trend in any one location.

\subsection{Future change analysis}

Figure $\mathrm{S} 3$ shows maps of the percentage change in 2- and 20-year return period 30-day duration low flows, between the BS median and the NF_adjrs and FF_adjrs medians. Figure S4 shows maps of the ratios of the percentage changes in 2- and 20-year return period 30-day duration low flows when using adjusted $r_{s}$ PE compared to using fixed $r_{s}$ PE. 

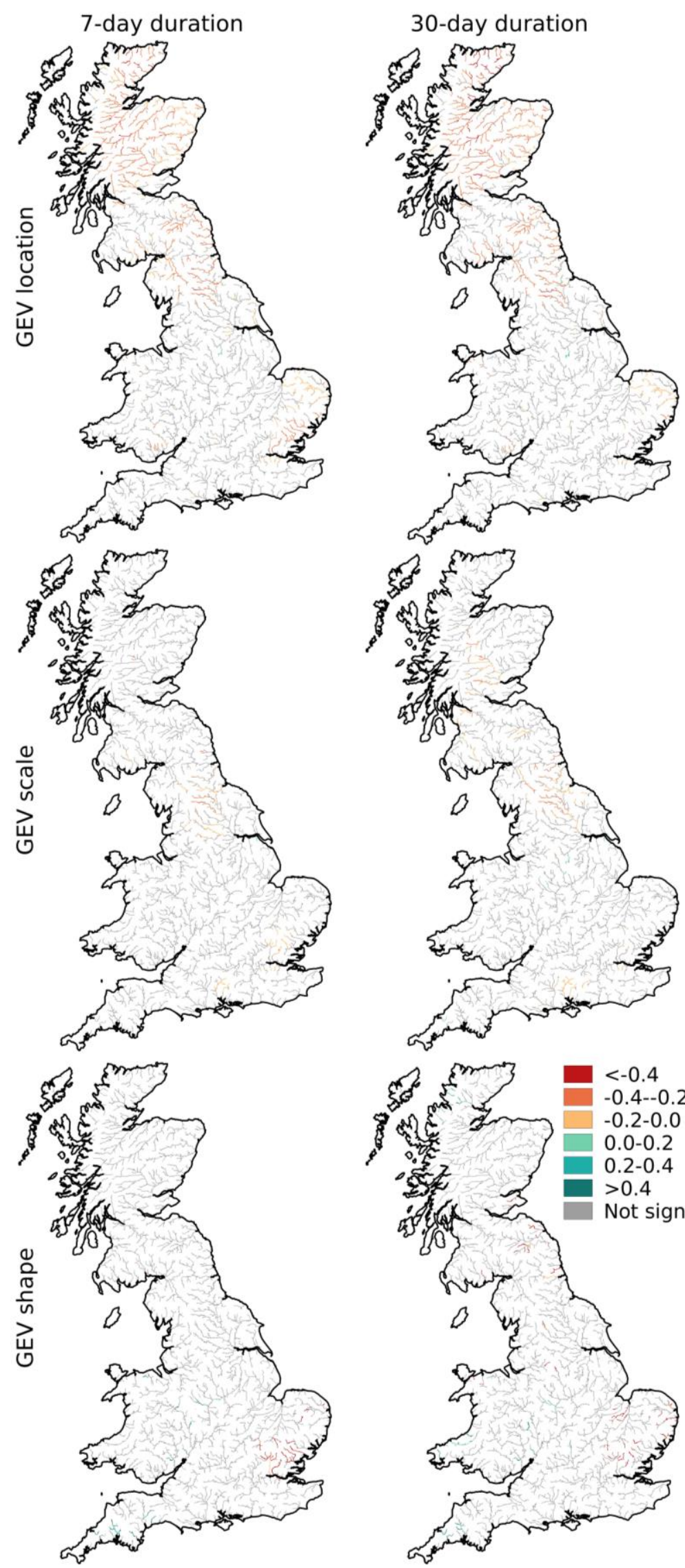

Figure S1 Maps of trends from the OBS run (scaled by the 2-year return period low flow from the last position of the moving window), for the GEV parameters for 7- and 30-day duration low flows. Trends that are not significant at the $10 \%$ level are greyed out. 


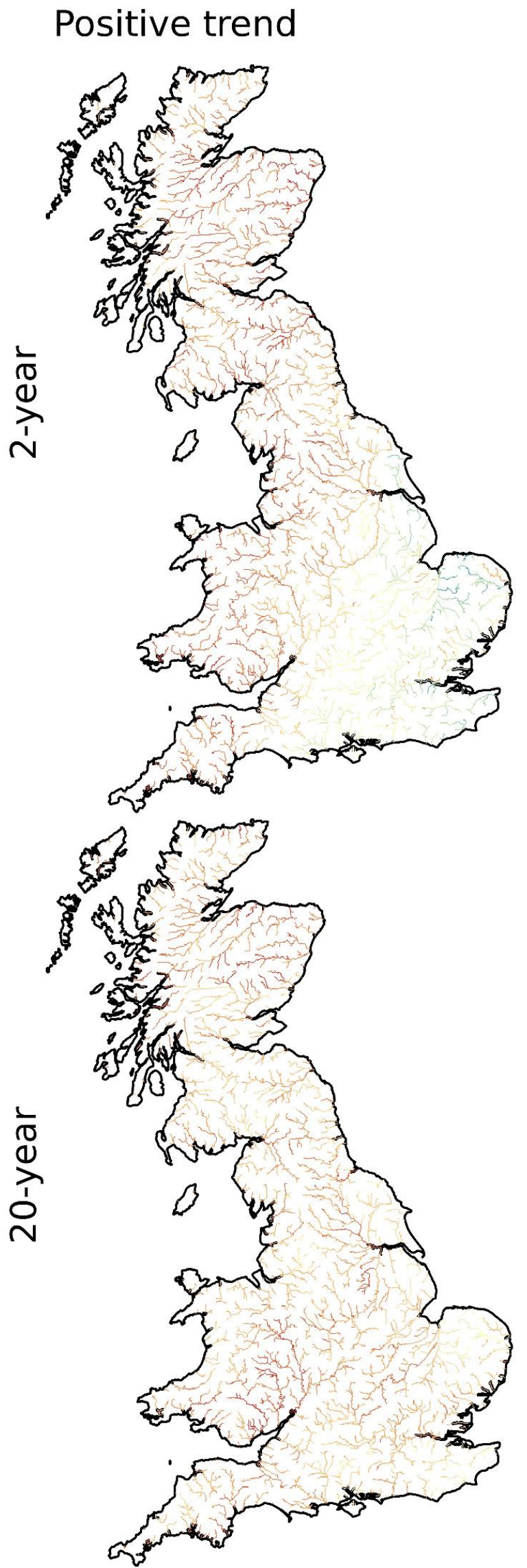

Negative trend

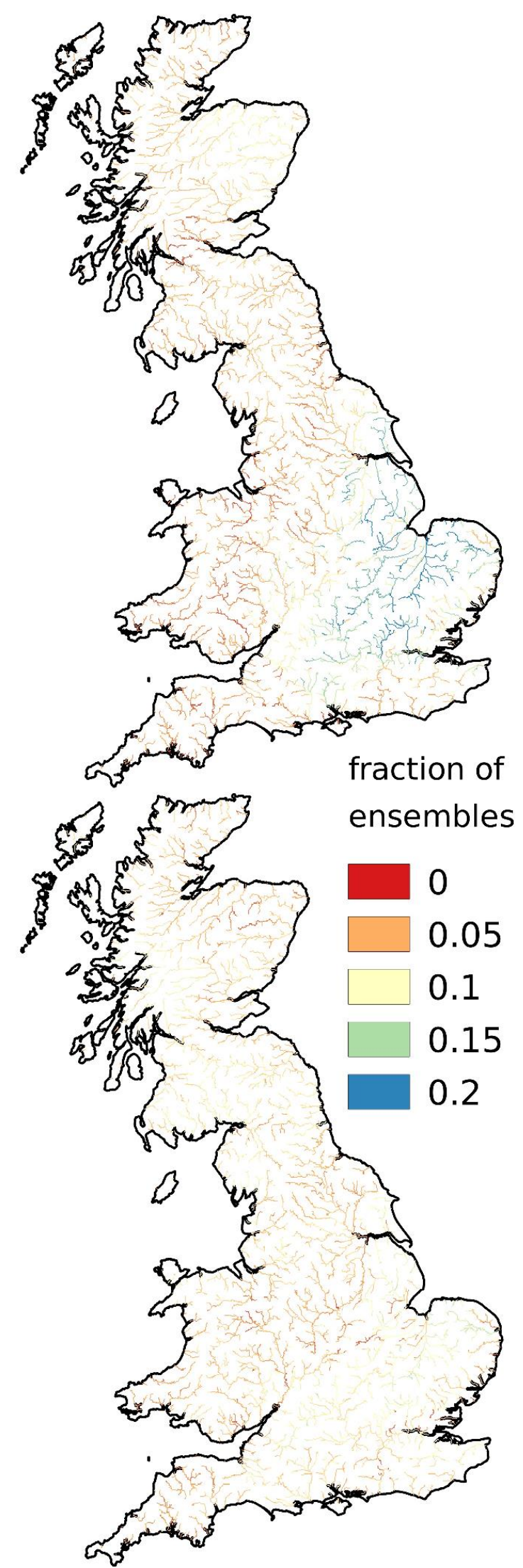

Figure S2 Maps of the proportion of HIST ensemble runs showing positive (left) or negative (right) trends (significant at the $10 \%$ level) in 2- and 20 -year return period 7-day duration low flows. 

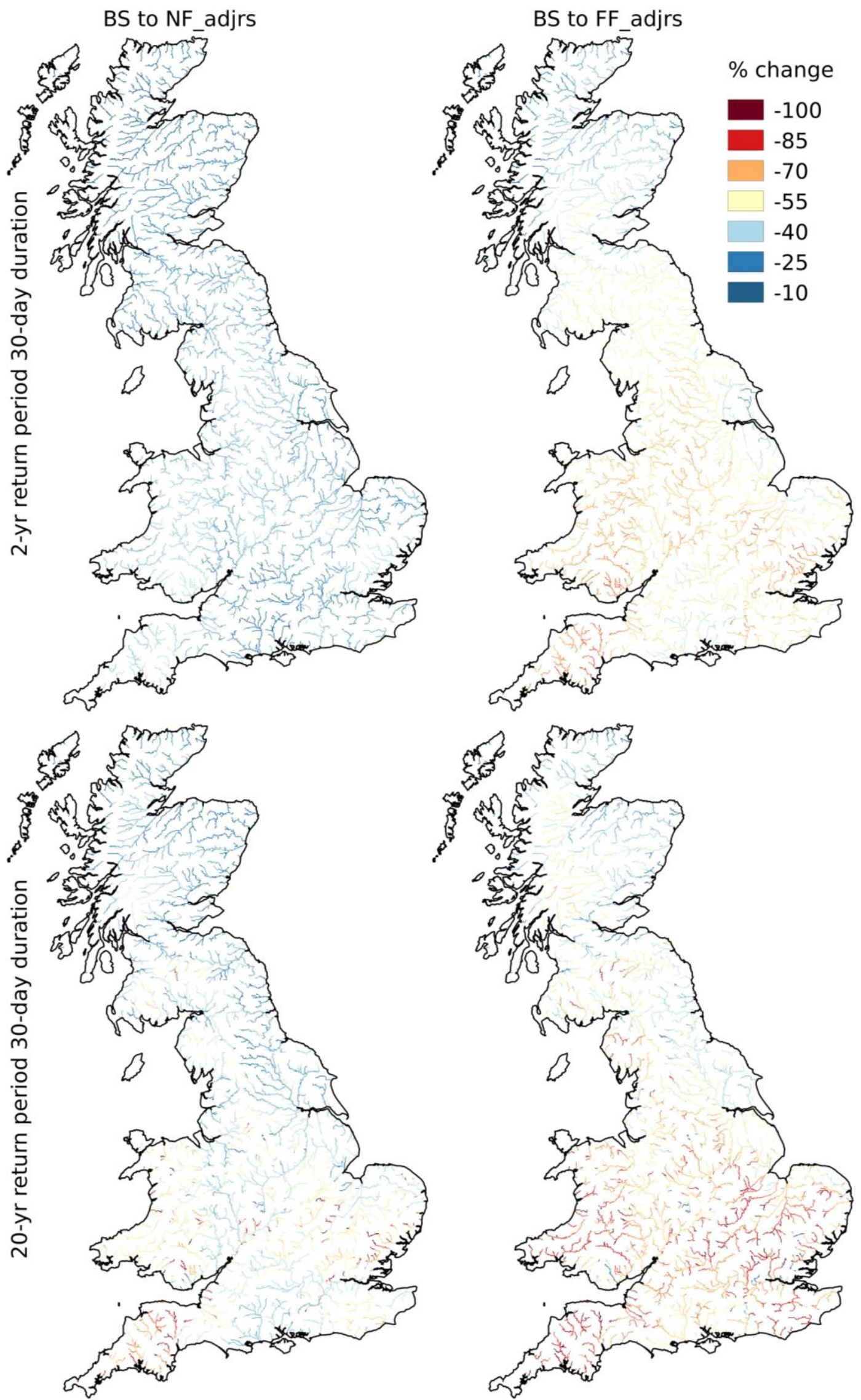

Figure S3 Maps of the percentage change in 2- and 20-year return period 30-day duration low flows, between the BS ensemble median and the NF_adjrs and FF_adjrs ensemble medians (left and right respectively). 

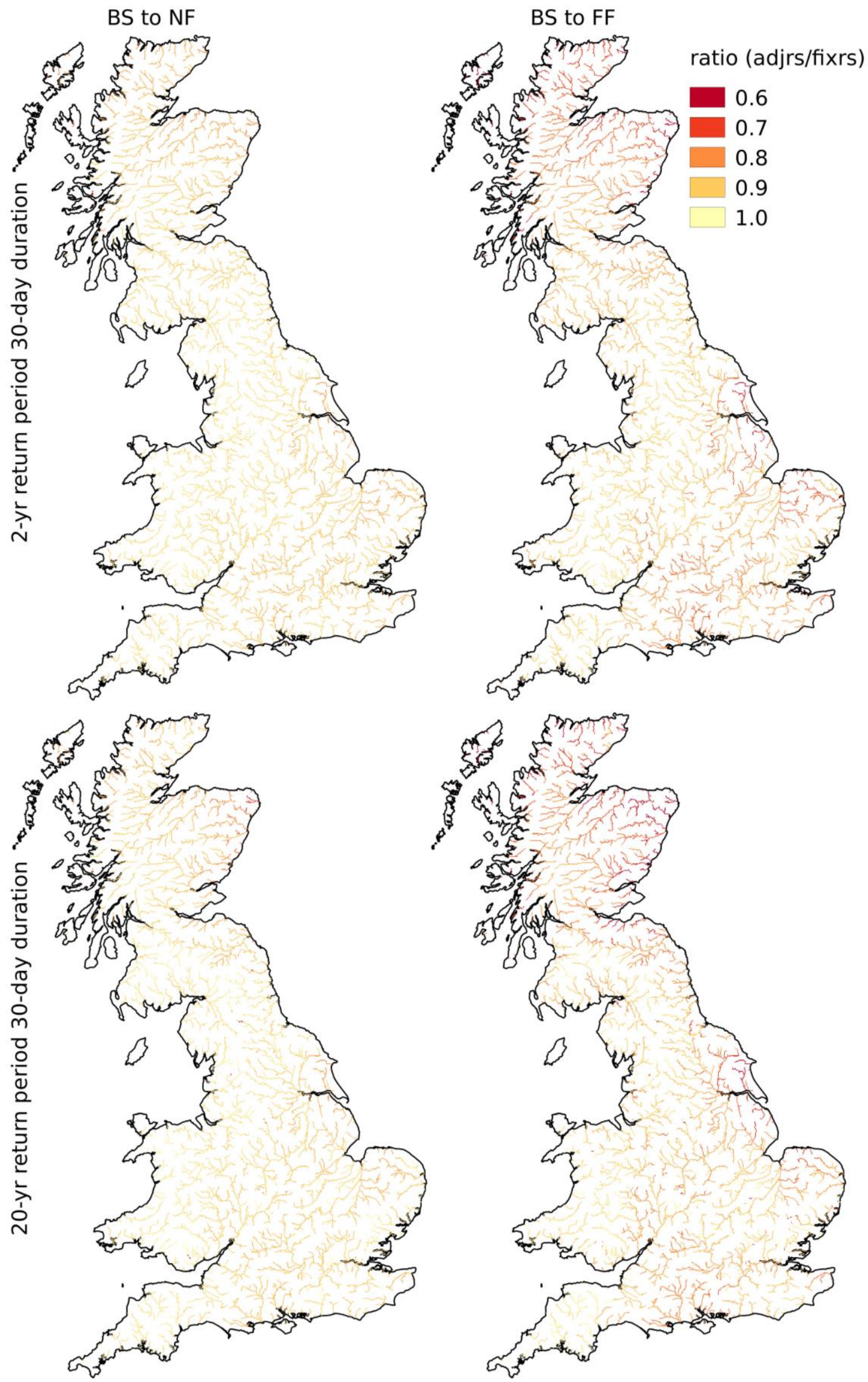

Figure S4 Maps showing the ratios of the percentage changes in low flows when using varying and fixed stomatal resistance (left, NF_adjrs / NF_fixrs; right, FF_adjrs / FF_fixrs), for 2- and 20-year return period 30-day duration low flows. 